\title{
Roll Motion of a Roro-Ship in Irregular Following Waves
}

Jianbo Hua

Royal Institute of Technology, Division of Naval Architecture, Sweden

Wei-Hui Wang

Professor, Department of System Engineering and Naval Architecture, National Taiwan Ocean University, Keelung, Taiwan, R.O.C.

Follow this and additional works at: https://jmstt.ntou.edu.tw/journal

Part of the Engineering Commons

\section{Recommended Citation}

Hua, Jianbo and Wang, Wei-Hui (2001) "Roll Motion of a Roro-Ship in Irregular Following Waves," Journal of Marine Science and Technology. Vol. 9: Iss. 1, Article 5.

DOI: $10.51400 / 2709-6998.2433$

Available at: https://jmstt.ntou.edu.tw/journal/vol9/iss1/5

This Research Article is brought to you for free and open access by Journal of Marine Science and Technology. It has been accepted for inclusion in Journal of Marine Science and Technology by an authorized editor of Journal of Marine Science and Technology. 


\title{
ROLL MOTION OF A RORO-SHIP IN IRREGULAR FOLLOWING WAVES
}

\author{
Jianbo Hua* and Wei-Hui Wang**
}

Keywords: roll motion, parametric excitation, irregular following waves, nonlinear GM-variation, Volterra system.

\section{ABSTRACT}

A RoRo-ship usually has a fine hull form with large flare at bow and stern. In order to achieve large cargo space, large ratio of the beam to draught are quite common for this kind ship. Such a hull configuration can be subjected to considerable variation of the metacentre height as she sailing in waves. As a consequence the parametric excitation becomes considerably great so that a large roll motion appears. This is a strongly nonlinear problem.

A simplified model is formulated in this paper to take account for the parametrically excited roll motion of a RoRo-ship in irregular following waves. The nonlinear parametric excitation is approched by a Volterra system. Monte-Carlo simulations are used to analyse the two most probable roll modes of a RoRo-ship due to the parametric excitation. The numerical result of the studied ship shows that the nonlinear parametric excitation has to be taken into account for the assessment of the roll motion behaviour. The parameter study related to the significant wave height and wave period has shown that a large roll motion can take place to the ship in reality with an non-negligible probability depending upon the wave statistics of the service sea area.

\section{INTRODUCTION}

Modern RoRo-ships have low block coefficient, large aspect ratio of the beam to draught and large flare at forebody and stern. This unconventional hull form allows large cargo space and high service speed. However, these kinds of hull configuration can be subjected to considerable variation of the meta-centric height in waves, which can cause the ship a large roll motion due to the parametric excitation. The roll motion becomes severe as the meta-centric height GM in a regular wave varies with a frequency in a specific ratio, such as $2,1,1 / 2,1 / 3,1 / 4 \ldots \ldots$, to the natural roll frequency of the ship. Theoretically, the most dangerous case occurs when the specific ratio is equal to 2 . The

Paper Received Nov. 15, 2000. Author for Correspondence: Jianbo Hua. *Royal Institute of Technology, Division of Naval Architecture, Sweden **Professor, Department of System Engineering and Naval Architecture, National Taiwan Ocean University, Keelung, Taiwan, R.O.C. speciality of the parametrically excited roll motion is that the roll amplitude can grow up to a large magnitude within a few encountering wave periods. This is a resonance phenomenon. Since RoRo-ships and cruise ships have long natural roll period, often greater than 20 seconds, the parametrically excited roll motion takes place more probably in following waves. Actually, the parametric excitation in irregular following wave becomes more regular than in heading waves due to the forward speed effect on the encounter frequency.

Up to now, most studies of the parametrically excited roll motion in irregular waves are based upon the assumption that the parametric excitation is a linear stochastic process and characterised by a spectral density function. Haddara (1980) analysed the problem by using a combination of the method of slowly varying parameters and the stochastic averaging technique. An equation for describing the variance of the roll amplitude as a function of time was obtained. The condition for stable motion was then derived. Roberts (1982) studied the same problem, by formulating some simple expression for the stationary response distribution. For the case of linear damping it was found that the motion was unstable if the damping factor was sufficiently small. The inclusion of a quadratic damping term in the equation of motion was shown to limit the unstable motion predicted by the linear damping assumption.

However, the GM-variation has a nonlinear characteristics in relation to the wave amplitude and the degree of nonlinearity is strongly dependent upon the hull form. The numerical investigation into the GMvariation in regular and irregular waves by Palmquist (1994) has shown that the GM-variation in an irregular wave can be described by a sum of a linear Gaussian process and a nonlinear process respectively due to the higher order influence. Hua, Wang and Chang (1999) applied the theory of Volterra system to describe the GM-variation in irregular waves. The transfer functions of different orders could then be derived. The first order transfer function of a ship in following waves showed in good agreement with the result according to Palmquist's method. 
Luth and Dallinga (1998) reported a motion simulation result for a cruise vessel in irregular heading and following waves, based upon a mathematical model of six degrees of freedom. Roll angle up to 40 degrees was obtained. The predicted parametrically excited roll motion in different wave conditions was compared with model tests, which gave a fair agreement.

So far, the knowledge about the effect of irregular following waves on the roll motion is not yet sufficient. In fact, owing to the irregularity of ocean waves, it necessitates to consider this fact in order to assess the risk of large roll motion. In this study, a single nonlinear differential equation is utilised for the description of the parametrically excited roll motion in following waves. Monte-Carlo simulation technique is used for the time-domain simulation of the roll motion in irregular waves. Both the nonlinear roll damping and GM-variation will be considered. Emphasis of the investigation is put on the roll behaviour of a ship in irregular following waves with respect to the actual load condition. The main particulars of the investigated ship are that typical for modern RoRo-ships and cruise ships.

\section{METHOD}

\section{Roll motion equation}

Assume that the roll motion of a ship sailing in following waves takes place around a rotation axis so that it is not coupled with the sway and yaw motions. It is also assumed that the roll motion will not affect the heave and pitch motion while the later mentioned motions have an effect on the roll motion in term of parametric excitation due to the GM-variation. Hence, a differential equation of one degree of freedom can be used to express the roll motion as :

$$
\ddot{\phi}+D(\dot{\phi}) \cdot \dot{\phi}+\omega_{0}^{2} \cdot\left(1+\frac{G M(t)}{G M_{0}}\right) \cdot \phi=\omega_{0}^{2} \cdot \phi_{\text {bias }}
$$

where $D(\dot{\phi})$ represents the roll damping, $\omega_{0}$ the natural roll frequency in calm water, $G M_{0}$ the initial metacentric height and $G M(t)$ the GM-variation in waves. $\phi_{\text {bias }}$ is the bias heel angle which is assumed to be equivalent to,e.g., the effect of the wind pressure on the superstructure.

As known, the roll damping of a ship consists of five components. They are frictional damping, eddy damping, wave damping, lift damping and bilge keel damping. For a specific ship, model test is usually utilised to accurately quantify her roll damping. Besides, semi-empirical methods are also often used to estimate the roll damping as well, see Himeno (1981). Whilst, here the principal effect of the roll damping on the roll
Table 1. The nonlinear damping coefficients and the corresponding equivalent roll damping at 20 degree roll amplitude

\begin{tabular}{ccc}
\hline$\rho_{0}$ & $\rho_{1}$ & $\rho_{1}\left(20^{\circ}\right)$ \\
\hline 0.03 & 0.2363 & $10 \%$ \\
0.03 & 0.4050 & $15 \%$ \\
0.03 & 0.5738 & $20 \%$ \\
\hline
\end{tabular}

motion is investigated. The roll damping in (1) can be expressed in a simplified form as :

$$
D(\dot{\phi})=2 \cdot \omega_{0} \rho_{0}+2 \cdot \rho_{1} \cdot|\dot{\phi}|
$$

where $\rho_{0}$ is the coefficient of the linear damping part, and $\rho_{1}$ for the quadratic part.

Equivalent roll damping coefficient is defind as a linearized form of the nonlinear roll damping with an equivalint damping energy, i.e.,

$$
\rho_{e}\left(a_{\phi}\right)=\rho_{0}+\frac{8}{3 \cdot \pi} \rho_{1} \cdot a_{\phi}
$$

so that

$$
D(\dot{\phi})=2 \cdot \omega_{0} \cdot \rho_{e}\left(a_{\phi}\right)
$$

where $a_{\phi}$ is the expected roll amplitude.

In this study, the equivalent roll damping coefficient is used as a measure for nonlinear roll damping. Three nonlinear damping coefficients are used in the roll motion simulation. Their relations to the equivalent roll damping coefficient at 20 degree roll amplitude are shown in Table1.

The nonlinear roll damping corresponding to an equivalent roll damping coefficient $15 \%$ at 20 degree roll amplitude is considered to be reasonable for the analysis and generally used in this study.

\section{Description of irregular waves}

The wave energy spectrum for a short-term sea with a duration of about 2-4 hours is usually assumed to be constant in its spectrum form. The linear wave theory is used here for the description of wave motions. According to the theory, an irregular sea is assumed to be a wave system consisting of a number of regular wave components. The phase lags between the regular wave components change at random. To describe an irregular wave motion mathematically in time-domain, one divides the wave energy spectrum $S(\omega)$ into $N$ components $\Delta S(\omega)$ between $\omega_{0}-\frac{\Delta \omega}{2}$ and $\omega_{0}+\frac{\Delta \omega}{2}$. Thus, the amplitudes of the regular wave components are determined according to: 


$$
a_{n}=\sqrt{2 \cdot \Delta S\left(\omega_{n}\right)}=\sqrt{2 \cdot \int_{\omega_{n}-\Delta \omega / 2}^{\omega_{n}+\Delta \omega / 2} S(\omega) \cdot d \omega}
$$

The wave elevation of an irregular long-crested wave in the coordinate system with origin fixed at the mass centre of a ship becomes;

$$
\begin{aligned}
\eta(x, t) & =\sum_{n=1}^{N} a_{n} \cdot \cos \left(k_{n} \cdot(x \cdot \cos \beta+y \cdot \sin \beta)\right. \\
& \left.-\omega_{e, n} \cdot t+\beta_{n}\right)
\end{aligned}
$$

where the wave number $k_{n}=\omega_{n}^{2} / g=2 \pi / \lambda_{n}$ and $\beta_{n}$ is the random wave phase following an uniform distribution between $(-\pi, \pi) . \quad \beta$ is the incident angle of the wave.

A mean JONSWAP-spectrum considered the significant wave height $H_{1 / 3}$, modal period $T_{p}$ and peak enhancement factor $\gamma$ as independent parameters was used to represent the wave energy spectrum in this study. It is a simplified one of the original JONSWAPspectrum defined by five parameters. Thus the mean JONSWAP-spectrum is given by

$$
\begin{aligned}
& S_{\text {Jonswap }}\left(H_{1 / 3}, T_{P}, \gamma, \omega\right) \\
& =S(\omega)_{P M} \cdot \gamma^{\beta} \cdot\left[\frac{H_{1 / 3}^{2}}{16 \cdot \int_{0}^{\infty} S(\omega)_{P M} \cdot \gamma^{\beta} \cdot d \omega}\right]
\end{aligned}
$$

where:

$$
\begin{aligned}
& \beta=e^{-\left|\frac{\left(\omega-\omega_{n}\right)^{2}}{2 \cdot \sigma^{2} \omega^{2}{ }_{m}}\right|} \text { where } \sigma= \begin{cases}\sigma_{a}=0.07 & \omega \leq \omega_{m} \\
\sigma_{b}=0.09 & \omega \geq \omega_{m}\end{cases} \\
& S(\omega)_{P M}=\frac{A}{\omega^{5}} \cdot e^{-B / \omega^{4}}, \\
& A=\frac{123.95 \cdot H_{1 / 3}^{2}}{\bar{T}^{4}} \\
& B=\frac{495.8}{\bar{T}^{4}} \\
& \bar{T}=0.711 \cdot T_{p}
\end{aligned}
$$

$\omega_{m}$ denotes the modal frequency. When the peak enhancement factor $\gamma=1$, it becomes a P-M spectrum. The wave energy becomes more concentrated around the modal frequency with increasing $\gamma . \gamma=3.3$ is generally used in this study, if not noted. Thus, a wave condition can be defined by two independent parameters, namely the significant wave height and modal period.

\section{GM-variation as a Volterra system}

A ship running at sea will generate radiation and diffraction waves. However, these waves are in lower order of magnitude in comparison with the incident wave, especially when the ship runs in a following waves. Here, only the pressure of incident wave potential and the change of the hydrostatic pressure due to the ship motions are taken into account for the calculation of the GM-variation.

In this study, the GM-variation in waves is approached by a Volterra system derived in [4]. The GMvariation is then expressed as:

$$
\partial G M(t)=\sum_{i} \partial G M_{i}(t)
$$

where

$$
\begin{aligned}
\partial G M_{1}(t) & =\sum_{n=1}^{N} a_{n} \cdot\left[f_{1}\left(\omega_{n}\right) \cdot e^{-i \cdot\left(\omega_{n} \cdot t+\beta_{n}\right)}\right. \\
& \left.+f_{1}^{-}\left(\omega_{n}\right) \cdot e^{i \cdot\left(\omega_{n} \cdot t+\beta_{n}\right)}\right]
\end{aligned}
$$

and

$$
\begin{aligned}
\partial G M_{2}(t) & =\sum_{m=1}^{M} \sum_{n=1}^{N} a_{m} \cdot a_{n} \cdot\left[u_{2}\left(\omega_{m}, \omega_{n}\right)\right. \\
& \cdot e^{-i \cdot\left[\left(\omega_{m}+\omega_{n}\right) \cdot t+\beta_{m}+\beta_{n}\right]} \\
& \left.+u_{2}\left(\omega_{m}, \omega_{n}\right) \cdot e^{-i \cdot\left[\left(\omega_{m}-\omega_{n}\right) \cdot t+\beta_{m}-\beta_{n}\right]}\right] \\
& +\sum_{m=1}^{M} \sum_{n=1}^{N} a_{m} \cdot a_{n} \cdot\left[v_{2}\left(\omega_{m}, \omega_{n}\right)\right. \\
& \cdot e^{i \cdot\left[\left(\omega_{m}-\omega_{n}\right) \cdot t+\beta_{m}-\beta_{n}\right]} \\
& \left.+v_{2}\left(\omega_{m}, \omega_{n}\right) \cdot e^{i \cdot\left[\left(\omega_{m}+\omega_{n}\right) \cdot t+\beta_{m}+\beta_{n}\right]}\right]
\end{aligned}
$$

etc.

$f_{1}\left(\omega_{n}\right)$ and $f_{1}^{-}\left(\omega_{n}\right)$ are the first order complex transfer functions for the GM-variation. $u_{2}\left(\omega_{m}, \omega_{n}\right)$, $u_{2}^{-}\left(\omega_{m}, \omega_{n}\right), v_{2}\left(\omega_{m}, \omega_{n}\right)$ and $v_{2}^{-}\left(\omega_{m}, \omega_{n}\right)$ are the second order complex transfer functions. Detail information about the calculation of the transfer functions can be found in [4]. In the following roll motion simulation, only the first two order GM-variations are taken into account, since the higher order ones are very small and can be neglected in comparison with the first two ones.

For calculating the heave and pitch motions of a ship in following waves, the linear motion theory is assumed to be available, i.e. the motions are proportional to the wave amplitude in a regular wave. The extraordinary strip theory derived by Salvesen, Tuck and Faltisen (1970), is applied to the calculation of the heave and pitch motions. Although the linear strip theory can not attain an accurate calculation of the radiation and diffract forces in following waves, but the accuracy of the calculated motions are still acceptable 
since the Froude-Krylov forces and the hydro-restoring forces, which have the predominant effect on the motions, can still accurately calculate.

\section{Monte-Carlo simulation}

For the probabilistic study of the roll motion, Monte-Carlo simulation technique is applied. In order to get the curves regarding the roll amplitude versus the probability of exceedance, the total real-time of 50000 seconds is taken and divided into 50 time series. Within each time series, the roll motion is determined by the time-integration of equation (1), using a lower order Runge-Kutta method. A set of random wave phases $\beta_{n}$ $(n=1,2, \ldots)$ is used in equation (5) to generate the irregular wave motion and consequently the irregular time dependent GM-variation. The set of random wave phases changes from one time series to another using a random number generator.

A bias heel angle of 3 degrees is used to initiate the roll motion in irregular following waves. The later presented in curves for the roll amplitude as function of probability of exceedance are obtained by polynomialfitting to the ones of the simulated roll amplitude distribution.

\section{RESULT AND DISCUSSION}

The hull form of a studied RoRo-ship is shown in Fig. 1. The main particulars are:

$\begin{array}{ll}\text { Lpp } & 137.40 \mathrm{~m} \\ \mathrm{~B} & 24.20 \mathrm{~m} \\ \mathrm{~T} & 5.60 \mathrm{~m} \\ \mathrm{~V}_{\max } & 21.00 \text { knots }\end{array}$

\section{Parametrically excited roll motion for $\omega_{e} / \omega_{n} \approx 2$}

In regular waves, the parametrically excited roll motion is most sensitive to the GM-variation with the ratio of variation frequency to the natural roll frequency

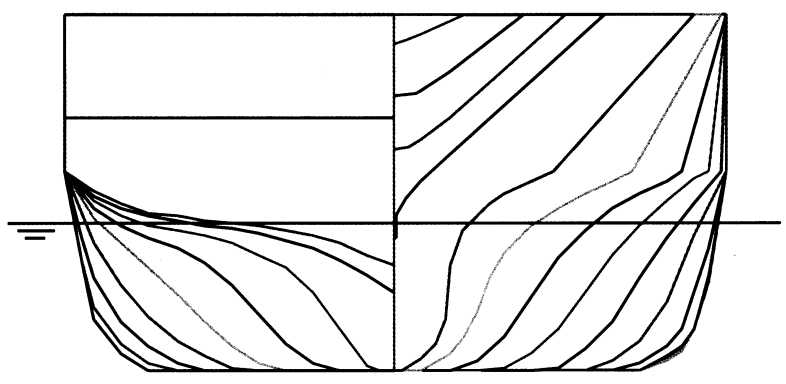

Fig. 1. The hull form of the RoRo-ship. equal to two. For irregular waves, it is appropriate to use the zero-cross mean variation frequency as a substitute to the variation frequency. The studied ship has a natural roll period of about 24 seconds at its actual load condition. It means that the required zero-cross mean variation period should be around $12 \mathrm{~s}$. According to the theory of Volterra system, the GM-variation can be expanded into series of different order. The numerical result shows that the zero-cross mean variation period of the first order GM-variation varies slightly above 10 seconds for the range of wave modal period between 8 and 16 seconds when the ship runs at 5 knots in following waves. Since the first order GM-variation is dominent, its mean variation period can represent the whole GM-variation.

For the parametric study, let's consider the effects of significant wave height, zero-cross mean wave period and roll damping on the roll motion. Fig. 2 shows the probabilities of exceedance for the roll angle in three wave conditions with significant wave height of 3 , 4 and $5 \mathrm{~m}$ respectively. The zero-cross mean wave period is 9 seconds and the same for all the three wave conditions. As seen, the $3 \mathrm{~m}$ significant wave height results in a most expected maximum roll amplitude of about 45 degree at the probability of $10^{-2.5}$. The probability of $10^{-2.5}$ means occurrence of one time under 2.1 hours. However, the expected maximum roll amplitude increases slightly with the increased significant wave height. The most expected maximum roll amplitudes are about 48 degrees for the two significant wave heights, $4 \mathrm{~m}$ and $5 \mathrm{~m}$ respectively. The reason is that the second order GM-variation increases faster than the first order one and the sufficiently large significant

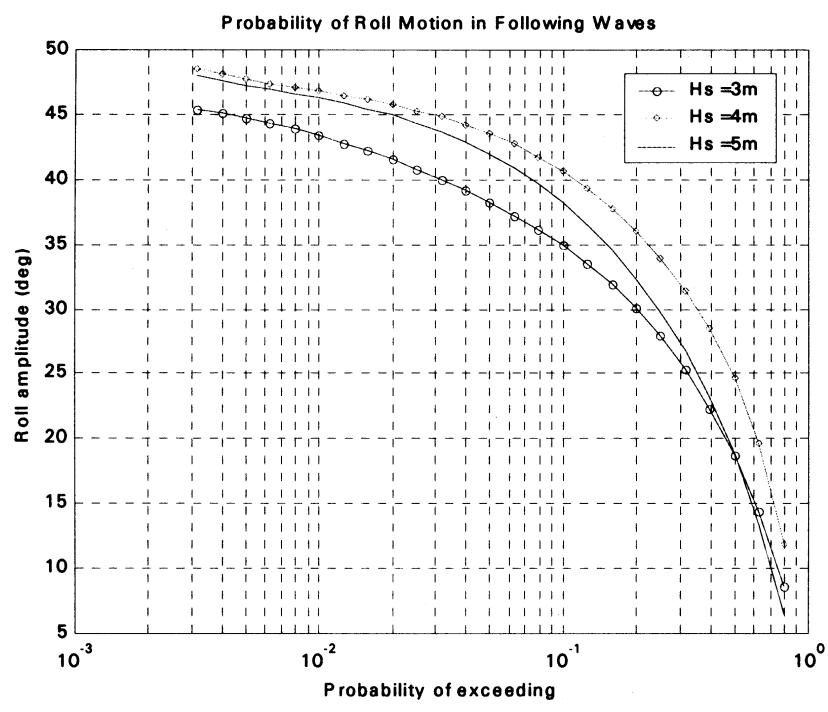

Fig. 2. Effect of significant wave height on the roll motion of the ship at 5 knots in irregular following waves. The modal wave period is $9 \mathrm{~s}$. 


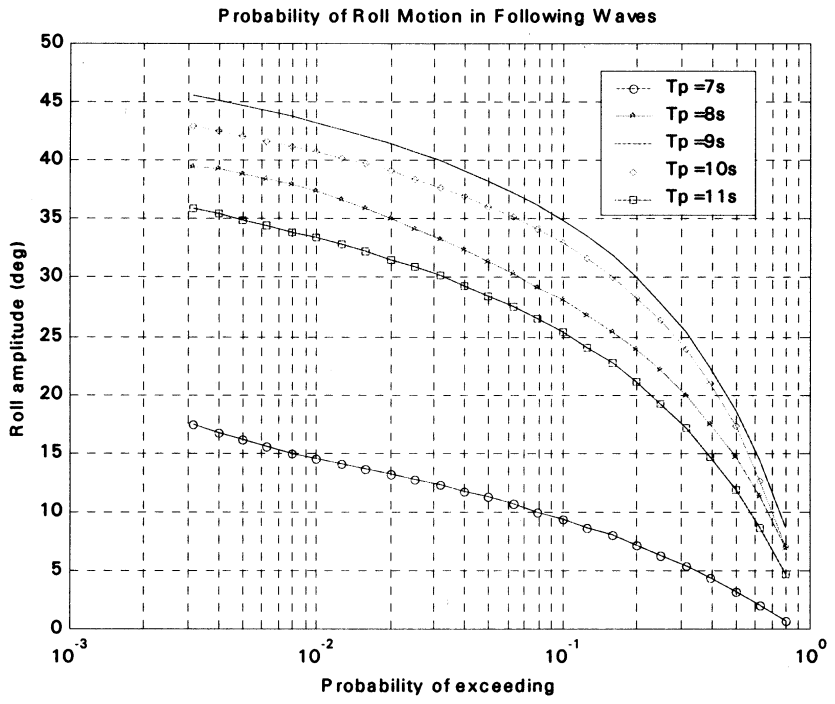

Fig. 3. Effect of modal wave period on the roll motion of the ship at 5 knots in irregular following waves. The significant wave height is $3 \mathrm{~m}$.

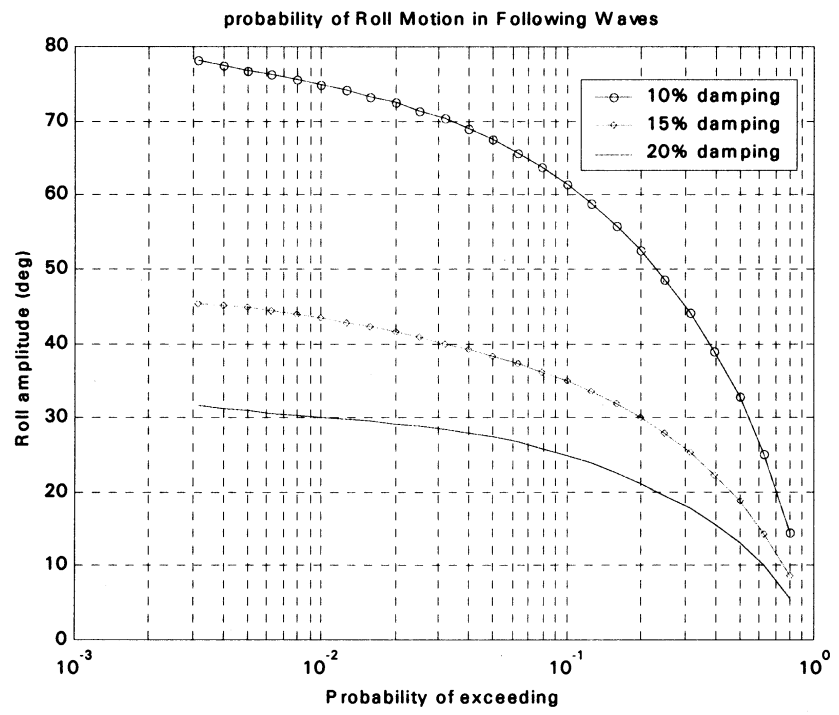

Fig. 4. The effect of roll damping on the probability of roll motion of the ship at 5 knots in irregular following waves. The signficant wave height is $3 \mathrm{~m}$ and the modal period $9 \mathrm{~s}$.

wave heights counteract the increase of roll amplitude.

The effect of modal wave period on the roll motion is shown in Fig. 3 for the wave modal periods from $7 \mathrm{~s}$ to $11 \mathrm{~s}$. The significant wave height is taken 3 meter for all cases. As shown, the most expected maximum roll amplitudes at the probability of $10^{-2.5}$ vary within the range between 35 to 45 degrees except for the modal wave period of 7 s. Fig. 3 together with Fig. 1 indicates that large roll motion due to parametric excitation can take place to the ship in reality with a non-negligible

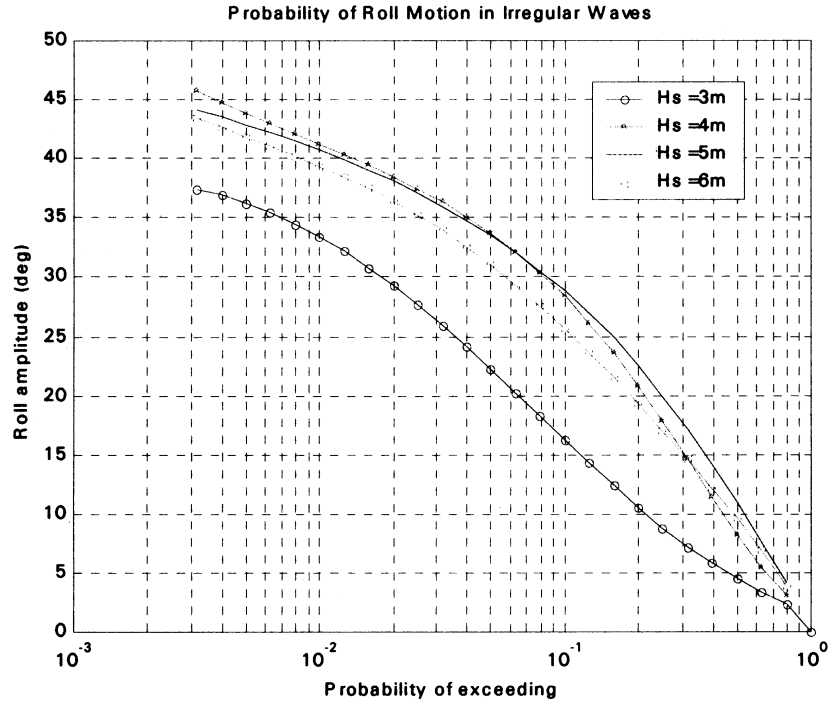

Fig. 5. Effect of significant wave height on the roll motion of the ship at 15 knots in irregular following waves. The modal wave period is $9 \mathrm{~s}$.

probability depending upon the wave statistics of the service sea area.

The roll damping effect on the roll motion is investigated through the simulations of three damping levels, namely $10 \%, 15 \%$ and $20 \%$ equivalent roll damping at 20 degree roll angle. The result is shown in Fig. 4. Obviously, the roll damping has a significant effect on the roll magnitude. The $10 \%$ equivalent roll damping results in a roll amplitude near 80 degrees at the probability of $10^{-2.5}$, while about 45 degree for $15 \%$ damping and 32 degrees for $20 \%$ one.

\section{Parametrically excited roll motion for $\omega_{e} / \omega_{n} \approx 1$}

Parametrically excited roll motion can also take place when the variation frequency of the first order GM-variation is near the natural roll frequency. However, the required magnitude of the GM-variation has to be greater than the previous case of $\omega_{e} / \omega_{n} \approx 2$. Since the GM-variation is nonlinear, the second order GM-variation has a high frequency part, which varies with a mean frequency about twice the first order GMvariation according to the theory of Volterra system [4] and [8]. So, the ship is subjected to two simultaneous parametric excitations, namely one with the frequency ratio $\omega_{e} / \omega_{n} \approx 1$ and the other with $\omega_{e} / \omega_{n} \approx 2$.

The effect of significant wave height on the roll motion is shown in Fig. 5. The simulation is carried out for four wave conditions with significant wave height of $3,4,5$ and $6 \mathrm{~m}$. The modal wave period is 9 seconds for the four wave conditions and the ship runs at 15 knots in following waves so that the zero-cross mean period of 


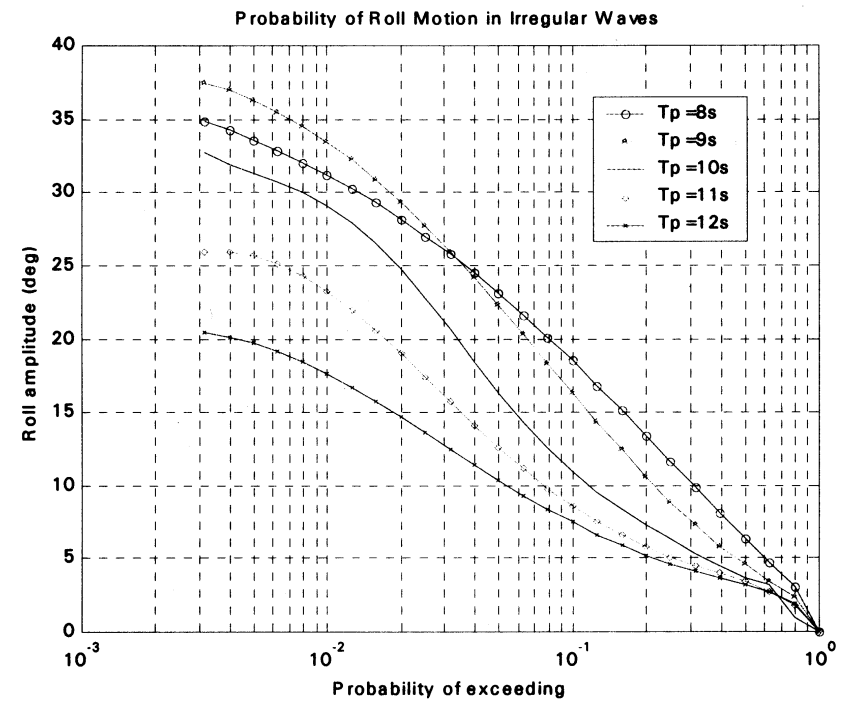

Fig. 6. Effect of modal wave period on the roll motion of the ship at 15 knots in irregular following waves. The significant wave height is $3 \mathrm{~m}$.

the first order GM-variation becomes to be 20 seconds for zero-cross mean wave periods between 8 to 16 seconds. The most expected maximum roll amplitudes under 2.1 hours are about 37, 46, 44 and 43 degrees for the four significant wave heights respectively. The result feature is similar to that as shown in Fig. 2, i.e. the roll amplitude does not increases with the higher significant wave height. The effect of modal wave period on the roll motion of the ship sailing at 15 knots in following waves is shown in Fig. 6. The modal wave periods of 8,9 and $10 \mathrm{~s}$ give the most expected maximum roll amplitudes over 30 degrees.

\section{CONCLUDING REMARKS}

The parametically excited roll motion of a RoRoship in irregular following waves is studied applying a mathematical model which takes into account both the nonlinear roll damping and the nonlinear GM-variation. The nonlinear GM-variation is represented by the Volterra system. The numerical result has shown that large roll motion can occur to the ship in moderate wave condition due to the wave-induced GM-variation. It is also indicated that the second order GM-variation is important to be taken into account for the roll motion. It is not necessary that higher significant wave height has to result in larger roll motion. A strongly non-linear GM-variation in severe waves can conteract the increase of roll motion in the form of changing natural roll period and distorting the effective parametric excitation.
Two most probable modes of the parametrically excited roll motion are examined. They are the cases for the mean frequency of the first order GM-variation has the ratio to the natural roll frequency of $\omega_{e} / \omega_{n}=2$ and $\omega_{e} / \omega_{n}=1$ respectively. Meanwhile, two parametric excitations with $\omega_{e} / \omega_{n}=1$ and $\omega_{e} / \omega_{n}=2$ acting on the roll motion simultaneously have been considered for the effect of the second order GM-variation.

Phenomenon of unstable roll motion has not been found from the simulation result. It can be explained by that a strongly nonlinear roll damping is assumed in the study. The dissipative energy due to the nonlinear roll damping grows always faster than the net energy generated by the parametric excitation when the roll amplitude becomes sufficiently large. The numerical result shows that the roll damping has a strong effect on the roll motion magnitude.

The parametric study regarding to significant wave height and wave period has shown that large roll motion due to parametric excitation can take place to the ship in reality with a non-nigligible probability dependent upon the wave statistics in the service sea area.

\section{REFERENCES}

1. Haddara, M. R., "On the Parametric Excitation of Nonlinear Rolling Motion in Random Seas," International Shipbuilding Progress, Vol. 27, No. 315, Nov (1980).

2. Roberts, J. B., "Effect of Parametric Excitation on Ship Rolling Motion in Random Waves," Journal of Ship Research, Vol. 26, No. 4, Dec (1982).

3. Palmquist, M. "On the statistical Properties of the Metacentric Height of Ships in Following Irregular Seas," STAB'94, Florida (1994).

4. Hua, J., W-H Wang and J-R Chang, "A Representation of GM-Variation in Waves by the Volterra System," Journal of Marine Scince and Technology, Vol. 7, No. 2 pp. 94-100 (1999).

5. Luth, H. R. and R. P. Dallinga, "Prediction of Excessive Rolling of Cruise Vessels in Head and Following Waves, " Proceeding of the 7th International Symposium on Practical Design of Ships and Mobel Inits, The Hague, The Netherlands, Sept (1998).

6. Salvsen N., E. O. Tuck and O. Faltinsen, "Ship Motions and Sea Loads," Trans. Vol. 78, SNAME (1970).

7. Himeno, Y., "Prediction of Ship Roll Damping - State of the Art," The University of Michigan, College of Engineering, Rep. No. 239, September (1981).

8. Rugh, W. J., "Non-linear System Theory - The Volterra/ Wiener Approach" The John Hopkins University Press, Baltimore and London (1981). 


\title{
駛上駛下船在不規則艉浪中之横搖
}

\section{運動}

\author{
華建 波
}

瑞典皇家工學院造船學門

王偉 輝

國立台灣海洋大學系統工程暨造船學系

\section{摘 要}

駛上駛下船通常其船型較瘦, 但在艄艉水線上 方有很大的舷緣外傾。這類船爲了獲得較大的載貨空 間一般其船寬—吃水比亦很大。如此之船體構形, 當 其航行於波浪中時, 將會產生相當大之定傾高變化, 隨之船體横搖振幅亦會變得甚大, 其運動分析屬強非 線性問題。

本文針對駛上駛下船在不規則艉浪中考虑參數 激振横搖運動, 推導簡化之分析模式。以伏特娜系統 來探討非線性參數激振現象, 並利用蒙地卡羅模擬分 析駛上駛下船最有可能因參數激振而造成之横搖模 式。就實船之數值分析結果顯示, 非線性參數激振現 象對横搖運動行爲之評估必須列入考虑。藉由有義波 高及波週期等之參數分析顯示, 駛上駛下船在實際狀 況產生大横搖角運動之可能性是存在而不可忽視的, 其機率端視服勤海域之波浪統計而定。 